\title{
Fissure Sealants - In Vitro Evaluation of Abrasion Wear and Superficial Roughness
}

\author{
Vanessa Pardi, Mário Alexandre Coelho Sinhoreti ${ }^{\mathrm{b} *}$, Antonio Carlos Pereira ${ }^{\mathrm{c}}$, \\ Gláucia Maria Bovi Ambrosano c, Marcelo de Castro Meneghim ${ }^{c}$ \\ aniversity of Sagrado Coração, Bauru - SP, Brazil \\ ${ }^{\mathrm{b}}$ Department of Restorative Dentistry, Dentistry College, University of Campinas - UNICAMP, \\ Av. Limeira, 901, 13414-903 Piracicaba - SP, Brazil \\ 'Department of Community Dentistry, Dentistry College, \\ University of Campinas - UNICAMP, Piracicaba - SP, Brazil
}

Received: February 24, 2006; Revised April 19, 2008

\begin{abstract}
The aim of this study was to compare the in vitro wear and superficial roughness of four materials (Delton Dyract Flow, Dentsply; Filtek Flow, Vitremer, 3M ESPE) used as fissure sealant in 32 extracted human molars divided in four groups $(\mathrm{n}=8)$ after abrasion with toothbrush/dentifrice. Impressions of each occlusal surface were made to analyze wear and circular specimens were prepared to analyze the roughness. Teeth and specimens were mounted in a toothbrushing machine. The replicas were observed using a SEM to determine the superficial wear. Wear: there were no statistically significant differences either between Delton and Filtek Flow or between Dyract Flow and Vitremer. Roughness: there were no statistical differences between Filtek Flow and Dyract Flow, Dyract Flow and Vitremer, Vitremer and Delton., Considering the clinical practice, if caries activity is present the use of Vitremer is suggested not only for its well known fluoride release, but it presented good roughness results.
\end{abstract}

Keywords: dental materials, pit and fissure sealants, preventive dentistry

\section{Introduction}

In the past years, there has been an observable decrease in caries incidence ${ }^{1,2}$. However, this disease concentrates on occlusal surfaces that are responsible for about 56 to $70 \%$ of the caries in children of 5-17 years of age ${ }^{3,4}$. A large number of studies have shown that the use of fissure sealant is efficient in preventing caries on these surfaces ${ }^{5}$.

Many materials have been developed for fissure sealing. However, some materials used to fill teeth can also be used as fissure sealant, i.e. flowable composite or flowable polyacid-modified resin composite a common material that most of the dentists have in their office. Some resin modified glass ionomers (RMGI) have been applied as fissure sealant ${ }^{6-10}$, although their manufacturer does not indicate them for this use. The advantage of the RMGI as well as glass ionomer cements is that they release fluoride ${ }^{11,12}$ that influences the demineralization and remineralization process ${ }^{13}$.

The retention and effectiveness of different materials applied as fissure sealant have been studied in vivo. However, dentists are unwilling to use this procedure in their clinical practice. Two of the main reasons cited are the low retention and high wear rates of these materials ${ }^{14}$.

The wear rate of a great number of restorative materials have been studied, nevertheless there are few studies about wear of different materials used as fissure sealant. This property is important since sealant is an extra coronal addition to the occlusal surface and its wear characteristics might be a little different from those that are found in restorative materials that are placed in cavities ${ }^{14}$.

Dental materials, restorative or fissure sealants, are directly affected by oral cavity conditions, such as saliva, foods, tooth brushing and chewing forces ${ }^{15}$. Laboratory studies are useful in providing information on fundamental wear mechanisms; however devices used in wear tests simulate one or two of the wear mechanisms that simultaneously occur in the mouth ${ }^{16}$. According to Morgan (2004) $)^{17}$ the development of an optimal surface polish reduces stain and plaque accumulation and minimizes wear.

The aim of this study was to compare the in vitro wear and roughness of different materials used as fissure sealant after abrasion with toothbrush and dentifrice. Considering the importance of tooth brushing to the maintenance of the oral health, the tested hypothesis in this experiment was that the resin-based materials would present the best results regarding wear and roughness after exposure to an abrasive wear test.

\section{Materials and Methods}

The project was submitted and approved by the Ethics Committee of the Dentistry College - University of Campinas (\#042/2002).

The materials tested in this study were:

- Unfilled resin-based sealant - Delton (Dentsply De Trey, Konstanz, Germany)

- Flowable composite - Filtek Flow (3M/ESPE - St Paul, MN, USA)

- Flowable polyacid-modified resin composite (PMRC) - Dyract Flow (Dentsply Caulk, Dentsply International Inc., Milford, DE, USA)

- Resin-modified glass ionomer (RMGI) - Vitremer (3M/ESPE - St Paul, MN, USA) 


\subsection{Wear evaluation}

Thirty-two extracted human third molars without filling, evidence of caries or cracks were stored in distilled water after extraction. Following this, they were cleaned using periodontal instruments and pumice prophylaxis. Then, the teeth were maintained in distilled water at $4{ }^{\circ} \mathrm{C}$. The teeth were randomly distributed in the following groups: De-Delton; FF-Filtek Flow; DF-Dyract Flow and Vit-Vitremer.

The sealants were applied after pumice prophylaxis of the occlusal surfaces and etching of the teeth with $37 \%$ phosphoric acid gel (Dentsply De Trey) for 15 seconds. Then, the teeth were rinsed with a spray of air/water. The sealants were applied according to the manufacturer instructions, with exception of Vitremer that was mixed in a powder / liquid proportion of $1: 2$, to obtain lower viscosity so that the mixture flows into the fissures ${ }^{8}$.

Impressions of each tooth were made using addition silicone (Aquasil - Dentsply De Trey) and filled with epoxy resin (Epoxide BÜHLER, Lake Bluff, IL, USA) after the placement of the materials. The teeth were stored at $37{ }^{\circ} \mathrm{C}$ at $100 \%$ relative humidity until the preparation with the tooth brushing machine.

\subsection{Roughness evaluation}

Eight circular specimens ( $3 \mathrm{~mm}$ in height and $5 \mathrm{~mm}$ in diameter) of each material were fabricated in an addition silicone mold to verify the roughness of the materials before and after the abrasion test. The instructions of the manufacturers were followed for handling the materials, except for Vitremer, which was prepared in a proportion of 1:2 powder/liquid ${ }^{8}$. The molds were filled with the material, covered with a polyester strip and a thin glass slab and when necessary, the specimens were light-cured (Photo Unit XL 1500 - 3M/ ESPE - St Paul, MN, USA) following the exposure time recommended by the manufacturer. Then, the specimens were polished with sandpaper $\left(600,1000\right.$ and 1200 grain), and were stored at $37^{\circ} \mathrm{C}$ at $100 \%$ relative humidity until the abrasion test.

The initial roughness measurement of the specimens was carried out using a Profilometer (SurfCorder SE 1700 - Kosaka Lab, Tokyo, Japan). Before the measuring, each specimen was gently dried with absorbent paper and air. The cut-off value was set at $0.25 \mathrm{~mm}$ and the surface roughness was characterized by the average roughness $(\mathrm{Ra})$. The Ra value was used because it represents the arithmetical average value of all absolute distances of the roughness profile from the center line within the measuring length ${ }^{18}$. Three readings were made on each surface using a stylus tip, which has a diameter of $2 \mu \mathrm{m}$. Each reading was obtained after turning the specimen $120^{\circ}$. The measurements were carried out before and after the abrasion test.

\subsection{Abrasion test}

The samples (sealed teeth and circular specimens) were submitted to mechanical tooth brushing, using a tooth brushing machine (Equilabor - Piracicaba, SP, Brazil) which can brush eight specimens concurrently.

Infantile toothbrushes with soft nylon bristles (Colgate ${ }^{\circledR}$ Classic Infantil - Kolynos ${ }^{\circledR}$ do Brasil, Ltda., Osasco, SP, Brazil) were used. The head was sectioned with a tungsten carbide bur and fixed in the toothbrush holder device of the machine using Super Bonder ${ }^{\circledR}$ (Loctite ${ }^{\circledR}$, SP, Brazil) fast setting adhesive. The samples were fixed on a plastic plate. The toothbrush was fixed perpendicular to the specimen surface. The test was made under a load of $200 \mathrm{~g}$, which was used to simulate the load of oral hygiene procedures.

Specimens were brushed in the presence of a dentifrice containing calcium carbonate (mean $6.5 \mu \mathrm{m}$ ) as an abrasive $\left(\right.$ Sorriso $^{\circledR}$ - Colgate ${ }^{\circledR}$ Classic Infantil - Kolynos ${ }^{\circledR}$ do Brasil, Ltda., Osasco, SP, Brazil) mixed with distilled water at a ratio of 1:1 in weight. The dentifrice was weighed on a precision balance. The specimens were subjected to linear tooth brushing movements across the specimens, at a speed of 250 cycles/minute, considering a double pass of the brush head over the surface, for 2 hours, totaling 30,000 cycles per specimen. This number of cycles corresponds to approximately 2 years of tooth brushing ${ }^{19}$. After the test, the specimens were removed, rinsed with tap water and stored at $37{ }^{\circ} \mathrm{C}$ at $100 \%$ relative humidity.

\subsection{Analysis of wear}

The sealed teeth were molded again as previously described. All the replicas in epoxy resin were observed in a scanning electron microscopy (SEM - LEO VP 435, Cambridge, United Kingdom) (x18) to evaluate the wear by comparison between the first and the second models. The area of assessment was the whole occlusal surface. The scores were: 0 - no change in the sealant surface; 1 ) polishing of the sealant surface without changes in the border; 2) polishing of the sealant surface with changes in the border and 3) sealant loss in some pit or fissure. Two examiners who were previously calibrated observed the images. They were blinded to the specimens. At this step the examiners observed different images of fissure sealant SEMs and discussed them until they reached an agreement.

\subsection{Statistical analysis}

The sample size was calculated considering a mean of roughness of 0.30 , a standard deviation of 0.04 , an $\alpha$-level of 0.05 and a test power of 0.90 . To observe a minimum difference of $2 \%$ it was considered necessary 8 specimens for each group in a total of 32 specimens.

The results of surface roughness were analyzed with repeatedmeasures analysis of variance, followed by the Tukey Test at the level of 5\% significance. Differences among the wear of the materials after the tooth brushing was analyzed using a Kruskal-Wallis with a Dunn multiple comparison test. The Kappa Test was employed to verify the inter-examiner reproducibility and the intraclass correlation coefficient to verify the intra-examiner reproducibility in regard to the wear evaluation.

\section{Results}

The wear of the models was evaluated by 2 examiners and the inter-examiner reproducibility was 0.85 , while the intra-examiner was higher than 0.90 .

The median and the mean rank of the wear of the materials can be observed in Table 1 . There were no statistically significant differences either between materials De and FF or between materials DF and Vit with the former showing the lower wear.

The mean roughness of the 4 materials, before and after the abrasion test, can be observed in Table 2. Statistically significant differences among materials FF, DF and Vit were not verified; De showed the roughest surface. After tooth brushing FF presented the highest roughness measurement and De and Vit, the lowest. For each material, statistical differences were observed for roughness before and

Table 1. Median and mean rank of the wear of the tested materials.

\begin{tabular}{lcc}
\hline \multicolumn{1}{c}{ Materials } & Median & Mean rank* \\
\hline Delton & 1 & $8.75 \mathrm{~b}$ \\
Filtek Flow & 1 & $8.81 \mathrm{~b}$ \\
Dyract Flow & 2 & $20.5 \mathrm{a}$ \\
Vitremer & 3 & $27.94 \mathrm{a}$ \\
\hline
\end{tabular}

Means followed by distinct letters are statistically different.

*The higher value the more wear that is seen. 
Table 2. Mean and standard deviation of the roughness of the tested materials before and after the abrasion using toothbrush and dentifrice.

\begin{tabular}{lcccc}
\hline \multirow{2}{*}{ Time } & \multicolumn{3}{c}{ Materials } \\
\cline { 2 - 5 } & Delton & Filtek flow & Dyract flow & Vitremer \\
\hline Before & $0.34(0.06) \mathrm{Aa}$ & $0.22(0.03) \mathrm{Bb}$ & $0.23(0.04) \mathrm{Bb}$ & $0.17(0.04) \mathrm{Bb}$ \\
After & $0.22(0.09) \mathrm{Cb}$ & $0.38(0.07) \mathrm{Aa}$ & $0.29(0.07) \mathrm{ABa}$ & $0.22(0.05) \mathrm{BCa}$ \\
\hline
\end{tabular}

Capital letters horizontally designate mean values with statistically significant differences for the material variable, while small letters vertically designate mean values with statistically significant difference for the time variable.

after the test which can be observed in Table 2. Delton demonstrated lower roughness after the abrasion test than before the test, which was the opposite of the other materials studied.

\section{Discussion}

Although fissure sealants have been considered effective in preventing occlusal caries ${ }^{20}$ and a great number of clinical studies about this procedure have been published, there are few studies about the wear resistance and the roughness of the different materials used as fissure sealants.

In the present study, four different types of dental materials were submitted to an abrasion test with toothbrush and dentifrice in vitro. Regarding wear, the sealed teeth with Vitremer and Dyract Flow showed the highest wear and there was no statistically significant difference between them. Vitremer is a resin modified glass ionomer (RMGI) and most of its physical properties are inferior to those of resin-based materials ${ }^{15,17}$. Vitremer and Dyract Flow are hybrid materials and contain variable quantity of resin in their structures, which are not exclusively polymerics. This explains why these materials have presented higher wear than Filtek Flow and Delton. According to Momoi et al., $1997^{22}$ this material is less abrasion resistant because of the lower surface hardness. El-Kalla \& García-Godoy, $1999{ }^{23}$ studied mechanical properties of compomers and suggested that compomer restorative material be placed between RMGI and composite in their study, since the tested materials "displayed the same arrangement of strength in both stages of the three-point bending test, the yield and flexural strength". However, Braem et al., 1995 ${ }^{24}$, concluded that the strength and flexural fatigue values of compomers are similar to the composites; a fact that could justify their use as a substitute for composites.

Wear is the least understood property of the restorative materials, since it involves different processes that can interact with each other $^{22}$. For this reason, in the present study only the abrasion with dentifrice and toothbrush was evaluated. The in vivo results probably differ since the fissure sealant is also affected by saliva, food and masticatory forces ${ }^{15}$.

There was no statistically significant difference between Delton and Filtek Flow in regards to wear in the present study. These materials are polymeric structures and the most important difference between them is the filler presence. Theoretically, unfilled materials demonstrate more wear than filled materials ${ }^{25}$ but in the present study differences between them were not observed. This result may have occured because in the mechanical tooth brushing machine the filler is not the main element that offers the wear resistance. The matrix may be more important in this case. Lugassy \& Greener $(1972)^{26}$ showed that the pattern of wear is different between an unfilled resin and a filled resin. According to them, the abrasion of an unfilled resin is lower and the wear is more uniform than that of a filled one.

Regarding roughness, Delton showed lower roughness measurement after tooth brushing than before the abrasion test. This fact confirms that the wear of an unfilled resin is more uniform than that of a filled resin ${ }^{26}$, since the roughness measurement of Filtek Flow increased after the test. The slurry used in this study had calcium carbonate as abrasive; particles of the filled resin detach and can act as an additional abrasive agent themselves, increasing the abrasion of the slurry ${ }^{27}$. Besides this, wear of the resin matrix allows particles of the filled resin to protrude and make the surface more irregular. This can explain the higher roughness of the Filtek Flow material after the abrasion test. In contrast, as Delton is an unfilled resin, it presented a lower roughness after this test.

There were no statistically significant differences amongst Filtek Flow, Dyract Flow and Vitremer regarding roughness before the test. According to El-Kalla \& García-Godoy, $1999^{23}$ hand-mixing materials do not produce the same surface as materials that are in paste form, such as composites and compomers. The low ratio of powder:liquid decreases the glass particles, which increases their susceptibility to erosion $^{28}$. In addition, the high roughness measurement to Vitremer can be a result of porosity caused by air bubbles in the material setting or by the particles exposed during abrasion ${ }^{29}$. The good results observed for this material before and after the abrasion test regarding roughness can be explained by the fact that this material is covered with a resin-based material (Finishing Gloss) after its setting.

Most clinical studies show that the resin-based material has the best retention rates ${ }^{19,30-33}$ in comparison to PMRC, RMGI and glass ionomer cement (GIC) when these materials are applied as fissure sealants. In vitro studies are useful to explain some conditions, of materials separate from when they are exposed in the mouth. Therefore, the results cannot be extrapolated to the clinical practice, since, as previously explained, several factors are acting on the dental materials at the same time. In the clinical practice, teeth with incipient caries or those that are not totally erupted in patients with caries activity should receive fissure sealant. In these cases, ionomeric materials (GIC and RMGI) are indicated for this treatment, since their capability of fluoride releasing is known. Even though a dental material releases fluoride, its surface should be sufficiently smooth in order to not accumulate substrate and microorganisms ${ }^{34}$. The Vitremer material showed good results regarding roughness in the present study.

With the methodology employed in this study, it was verified that between the modified materials Vitremer and Dyract Flow similar wear was observed as well as between Filtek Flow and Delton, however the wear of the former was higher. Vitremer and Delton showed lower roughness measurements after the abrasion test. . Considering the clinical situation, when caries activity is present the use of Vitremer is suggested as a fissure sealant, besides its well known fluoride release, in the present study along with Delton, it presented low roughness.

\section{Acknowledgements}

This study was supported by a grant from FAPESP - \#02/00156-6. The authors express their gratitude to Marcos Blanco Cangiani, technician of Dental Materials laboratory of the Dentistry College, UNICAMP, Piracicaba, Brazil. We are grateful to Thomas W. Brown III for his editorial assistance and proofreading for correct English. 


\section{References}

1. Truin GJ. Time trends in caries experience of 6- and 12-year-old children of different socioeconomic status in The Hague. Caries Research 1998; $32(1): 1-4$.

2. Vrbic V. Reasons for the caries decline in Slovenia. Community Dentistry and Oral Epidemiology 2000; 28(2):126-132.

3. Kaste LM, Selwitz RH, Oldakowski RJ, Brunelle JA, Winn DM, Brown LJ. Coronal caries in the primary and permanent dentition of children and adolescents 1-17 years of age: United States, 1988-1991. Journal of Dental Research 1996; 75(Spec no):631-641.

4. Meneghim MC, Saliba NA, Pereira AC. Importance of the first permanent molars in the determination of DMFT Index. Jornal Brasileiro de Odontopediatria - Odontologia do Bebê 1999; 2(5):37-41.

5. Ahovuo-Saloranta A, Hiiri A, Nordblad A, Worthington H, Mäkelä M. Pit and fissure sealants for preventing dental decay in the permanent teeth of children and adolescents. [CD - ROM 001830]. (Cochrane Review). Cochrane Database Syst Rev; 2004; n.3.

6. Luca-Fraga LR, Freire Pimenta LA. Clinical evaluation of glass-ionomer/ resin-based hybrid materials used as pit and fissure sealants. Quintessence International 2001; 32(6):463-468.

7. Pardi V, Pereira AC, Mialhe FL, Meneghim MC, Ambrosano GM. A 5-year evaluation of two glass ionomer cements used as fissure sealants. Community Dentistry and Oral Epidemiology 2003; 31(5):386-391.

8. Pereira AC, Basting RT, Pinelli C, Castro-Meneghim M, Werner CW. Retention and caries prevention of Vitremer and Ketac-Bond used as occlusal sealants after 6 and 12 months. American Journal of Dentistry 1999; 12(2):62-64

9. Raadal M, Utkilen AB, Nilsen OL. Fissure sealing with a light-cured resin-reinforced glass-ionomer cement (Vitrebond) compared with a resin sealant. International Journal of Paediaticr Dentistry 1996; 6(4):235-239.

10. Winkler MM, Deschepper EJ, Dean JA, Moore BK, Cochran MA, Ewoldsen N. Using a resin-modified glass ionomer as an occlusal sealant: a one year clinical study. Journal of American Dental Association 1996; 127(10):1508-1514.

11. Williams JA, Billington RW, Pearson GJ. A long term study of fluoride release from metal-containing conventional and resin-modified glassionomer cements. Journal of Oral Rehabilitation 2001; 28(1):41-47.

12. Silva KG, Pedrini D, Delbem ACB, Cannon M. Microhardness and fluoride release of restorative materials in different storage media. Brazilian Dental Journal 2007; 18(4):309-313.

13. Featherstone JDB. Prevention and reversal of dental caries: role of low level fluoride. Community Dentistry and Oral Epidemiology 1999; 27(1):31-40.

14. Pintado MR, Conry JP, Douglas WH. Fissure sealant wear at 30 months: new evaluation criteria. Journal of Dentistry 1991; 19(1):33-38.

15. Futatsuki M, Nozawa M, Ogata T, Nakata M. Wear of resin-modified glass ionomers: an in vitro study. Journal of Clinical Pediatric Dentistry 2001; 25(4):297-301.

16. Mair LH, Stolarski TA, Vowles RW, Lloyd CH. Wear: mechanisms, manifestations and measurement. Report of a workshop. Journal of Dentistry 1996; 24(1-2):141-148.
17. Morgan M. Finishing and polishing of direct posterior resin restorations. Practical Procedures and Aesthetic Dentistry 2004; 16(3):211-217.

18. Whitehead SA, Shearer AC, Watts DC, Wilson NHF. Comparison of methods for measuring surface roughness of ceramic. Journal of Oral Rehabilitation 1995; 22(6):421-427.

19. Aker JR. New composite resins: Comparison of their resistance to toothbrush abrasion and characteristics of abraded surfaces. Journal of American Dental Association 1982; 105(4):633-635.

20. Simonsen RJ. Pit and fissure sealant: review of the literature. Pediatric Dentistry 2002; 24(5):393-414.

21. McCabe JF. Resin modified glass-ionomers. Biomaterials 1998; 19(6):521-527.

22. Momoi Y, Hirosaki K, Kohno A, McCabe JF. In vitro tootbrush-dentifrice abrasion of resin-modified glass ionomers. Dental Materials 1997; 13(2):82-88.

23. El-Kalla IH, Garcia-Godoy F. Mechanical properties of compomer restorative materials. Operative Dentistry 1999; 24(1):2-8.

24. Braem MJ, Lambrechts P, Gladys S, Vanherle G. In vitro fatigue behaviour of restorative composites and glass ionomers. Dental Materials 1995; 11(2):137-141.

25. Christensen GJ. Sorting out the confusing array of resin-based composites in dentistry. Journal of American Dental Association 1999; 130(2):275-277.

26. Lugassy AA, Greener EH. An abrasion resistance study of some dental resins. Journal of Dental Research 1972; 51(4):967-972.

27. Attin T, Vataschki M, Hellwig E. Properties of resin-modified glassionomer restorative materials and two polyacid-modified resin composite materials. Quintessence International 1996; 27(3):203-209.

28. Gladys S, Van-Meerbeek B, Braem M, Lambrechts P, Vanherle G. Comparative physico-mechanical characterization of new hybrid restorative materials with conventional glass-ionomer and resin composite restorative materials. Journal of Dental Research 1997; 76(4):883-894.

29. Rios D, Honório HM, Araújo PA, Machado MA. Wear and superficial roughness of glass ionomer cements used as sealants, after simulated toothbrushing. Pesquisa Odontológica Brasileira 2002; 16(4):343-348.

30. Forss H, Halme E. Retention of a glass ionomer cement and a resin-based fissure sealant and effect on carious outcome after 7 years. Community Dentistry and Oral Epidemiology 1998; 26(1):21-25.

31. Mejäre I, Mjör IA. Glass-ionomer and resin-based fissure sealants: the clinical study. Scandinavian Jounal of Dental Research 1990; 98(4):345-350.

32. Poulsen S, Beiruti N, Sadat N. A comparison of retention and the effect on caries of fissure sealing with a glass-ionomer and a resin-based sealant. Community Dentistry and Oral Epidemiology 2001; 29(4):298-301.

33. Songpaisan Y, Bratthall D, Phantumvanit P, Somridhivej Y. Effects of glass ionomer cement, resin-based pit and fissure sealant and HF applications on occlusal caries in a developing country field trial. Community Dentistry and Oral Epidemiology 1995; 23(1):25-29.

34. Aranda M, García-Godoy F. Clinical evaluation of the retention and wear of a light-cured pit and fissure glass ionomer sealant. Journal of Clinical Pediatric Dentistry 1995; 19(4):273-277. 